\title{
The Construction and Practice of the Course Evaluation System Based on the Course of Engineering Drawing
}

\author{
Wenyu Zhao ${ }^{\text {a }}$, Haichen Zheng ${ }^{\text {b }}$, Zhonghu Gao ${ }^{\mathrm{c}}$ \\ School of civil engineering, Northwest Minzu University, Lanzhou730000, China \\ a565073924@qq.com, b563405632@qq.com, '664904755@qq.com
}

\begin{abstract}
The reform of the assessment mode is an important part of the teaching reform. This paper aims to change the past single assessment method. Taking the "Engineering Drawing" course as an example, we will explore a set of enthusiasm that can truly mobilize students and integrate teaching, learning and examination. New assessment system. The normal performance evaluation under the procedural management, the task-driven on-the-job experiment assessment, and the open-ended final exam questions focus on the students' flexible use of knowledge and the ability to solve practical problems. Promote learning by examination, and promote teaching by examination, in order to improve the learning effect and teaching quality of the "Engineering Drawing" course.
\end{abstract}

Keywords: teaching reform; engineering drawing; assessment system.

\section{Introduction}

The engineering drawing course is a compulsory technical basic course for all majors in civil engineering. Whether it is building houses, bridges, or building water conservancy hubs, in short, all engineering projects are inseparable from engineering drawings. The engineering drawings are drawn according to the unified standards set by the relevant state departments, and are the "language" of engineering and technical personnel to communicate technical ideas. Therefore, the ability to draw and read engineering drawings is a basic skill that all technicians must possess. The teaching task of this course is to train students to master the basic ability to draw and read civil engineering drawings. This course has a long history in engineering and is a traditional course.

The new era has put forward new requirements for the cultivation of talents. The capacity building of students and teachers has become the main theme of the reform of the system of education in China. The "Opinions on Deepening the Reform of Educational System and Mechanism" clearly states that "to strengthen the cultivation of students' key abilities" and "to improve the ability of personnel training in an all-round way" [1], in order to realize the professional engineering practice for understanding and evaluating complex engineering problems, The training objectives of the impact of social sustainable development, our institute has deepened the reform of engineering drawing courses. After the reform, the course consists of four methods: engineering form representation, reinforced concrete structure and steel structure drawing, professional drawing, drawing software AutoCAD basic usage and two-dimensional drawing. The module of professional drawing is divided into three parts: house building plan, road engineering drawing, bridge, culvert and tunnel engineering drawing. The course has 52 hours, including 32 hours of theoretical courses, 12 hours of on-campus, and 8 hours of practice. In the second semester of the freshman year, 3 credits, small class teaching.

The theory of graphics curriculum is difficult to teach, a little boring, and there are many homework after class. After the teaching reform, the original singularized closed-book examination is the leading evaluation method, so that teachers only pay attention to the teaching of theoretical knowledge and test-taking skills and neglect students. The cultivation of practical ability is obviously unable to meet the training objectives. It is urgent to explore a set of assessment system that can closely link theory with practice and fully mobilize students' enthusiasm to ensure that students can read engineering drawings and apply projection methods to express engineering shapes in future learning. 


\section{Construction of Engineering Drawing Course Assessment System}

\subsection{Process of the Usual Performance Assessment}

The usual grades account for $30 \%$ of the total scores, including classroom attendance and normal homework, of which classroom attendance accounts for $20 \%$, and usual homework accounts for $80 \%$. Engineering drawing is a very practical and practical course. The spatial thinking ability and practical ability need to be cultivated in a large number of graphic practice exercises. In the evaluation system, we have increased the proportion of daily performance, and deleted the past classroom performance. Questions such as questions that should not be quantified are replaced by the drawing of the usual engineering drawings. The usual assignment consists of four engineering drawings, which are required to be drawn on a uniform 2 to 3 A3 drawings. The frame, title bar, and text are all in accordance with the unified standard for building construction drawings _GB50001-2010. The four operations are to draw a section or section view of four shapes, draw a reinforced concrete beam drawing, and draw a house building drawing (including a building plan, elevation, section and detail). Draw bridge pier and culvert diagrams.

Ruler charting is the basic skill of engineering graphics and plays a pivotal role. The purpose of the homework is to enable the students to master the expression and graphic methods of the profile section, the reinforced concrete component diagram, the building construction drawing and the bridge culvert diagram through the basic training of the ruler drawing. The teacher scores from four aspects, and the content is drawn as required ( 20 points); the graphics are drawn accurately, the annotations are accurate, clear and beautiful, and the layers are distinct ( 60 points); the icon frame is correct, the font is beautifully written (10 points); Self-evaluation (10 points). The graphics are accurate, the annotations are accurate, clear and beautiful, and the hierarchy is the focus of the score. The teacher can make the accuracy (correct, basic correct, wrong) and integrity (complete, basic complete, incomplete) of each graphic. Score. Self-evaluation of drawings is an open process. Students are required to write a review of the knowledge of this chapter on the back or blank space of the drawings. The problems and experience in the process of drawing are summarized as long as the students write carefully. . The original intention of setting this link is to prevent students from drawing only to complete the homework, and to reflect on the knowledge points. At the same time, it is also helpful for the teachers to understand the degree of acceptance and confusion of the students, and to sort out and consolidate the common problems after the completion of the evaluation. The key to talent cultivation is teachers [2]. This work has increased the workload of the teachers. In order to mobilize the enthusiasm of the teachers, the workload of the correction of the drawings should be given quantitative assessment as appropriate.

\subsection{Task-driven Evaluation of the On-Machine Experiment}

In engineering practice, designers usually start with a sketch, and the heavy work of turning a sketch into a work drawing can be done by a computer. The graphics can be quickly made, so that the designer can make judgments and modifications to the design in time; Editing, zooming in, zooming out, panning, copying, and rotating related graphics data processing. For accurate drawing, the most widely used in China is AutoCAD software. Through the explanation and practice of CAD software in teaching, students can grasp the theoretical knowledge of CAD 2D modeling and plotting, and pay more attention to the cultivation of practical operation ability, and learn professional software such as Tianzheng Building and Midas. Lay the foundation.

The practice of software learning is very strong. Therefore, the task-driven teaching method is adopted in the teaching process. At the beginning of the course, the students are asked to complete the tasks to be completed in this lesson, and then according to the knowledge and ability required to draw the set of drawings, one by one. Complete the development of drawing commands, editing commands, layer creation, table style, text style, drawing standards and other skills and abilities. The first 4 class hours are designed to familiarize students with various commands and do some simple graphic drawing. After several hours of study, the students basically mastered the use of drawing commands and asked students to take professional drawings. For example, the fourth computer 
experiment, drawing the floor plan of the house, the work practice in front of this figure has been drawn with the ruler. With this foundation, the students can draw the method of drawing the floor plan, but the software drawing will appear again. New problems, including the use of layers, the drawing ratio of drawings are not referenced, the selection of line type and color is not standardized, and the label is incomplete. Drawing the "old map" with a new method, reinforce the knowledge point, and truly know the new one.

The assessment of the $\mathrm{CAD}$ drawing part requires changes to the traditional model and the implementation of the process assessment. Each time the computer class is arranged to draw professional drawings, the students complete a part of the class and the rest are completed after class. The teacher scores the drawings through several observation points, and each assignment has a chance to be modified. The teacher gives the total score after the error correction indicated by the teacher. In order to let students intuitively feel the improvement of their computer drawing ability, students are required to print out each job, bind to a book at the end of the period, and compare it with the ruler drawing work, and recognize the difference between ruler drawing and computer drawing, and establish a good relationship. Drawing order and concept. At the end of the period, we will conduct excellent job evaluations and exhibitions to stimulate students' enthusiasm for learning and cultivate a rigorous and scientific drawing spirit.

\subsection{Comprehensive Final Assessment}

Most of the college engineering drawing courses use the closed-book exam in the final exam. The exam content has the following problems.

(1) The examination subject assessment knowledge points are single, and the comprehensive application category has fewer topics.

(2) The content of the assessment is mainly based on the knowledge of books, and the assessment of students' ability to develop and innovate is less.

(3) The answers to the questions are mostly deterministic, and there are few open questions.

In response to the above questions, to improve the comprehensiveness and rationality of the test paper proposition, our teaching and research section has summarized the proportion of assessment knowledge points and test questions through nearly ten years of test paper feedback data. The expression of the engineering form gives the axonometric drawing of the shape, selects the expression and draws it (open question, the answer is not unique), accounting for $20 \%$; reinforced concrete member drawing and steel structure drawing, selecting, filling in the blank, replenishing the component, steel detail or steel sheet (comprehensive topic), accounting for $20 \%$; building plans, selection, fill in the blanks

Cross-section of the replenishment member, detailed steel bar or steel bar (comprehensive topic); bridge abutment and culvert tunnel picture (open question, the answer is not unique), accounting for $20 \%$; road engineering drawing, selection, Fill in the blanks, accounting for $5 \%$.

According to this proportion, the basic topics account for $60 \%$, open-ended questions, test questions for students to test innovation and flexible application ability accounted for $40 \%$. Propositions can inspire students' thinking and creativity as much as possible. For example, interpreting drawing questions and giving a few cue points can be different from standard answers, and can be scored if they are justified and meet the requirements of the questions.

\section{Practice of the Assessment System}

This assessment system was established in 2016 by the Architecture Teaching and Research Section of the School of Civil Engineering of Northwest University for Nationalities. It is applied to Class 1-4 of the 17th grade civil engineering majors. Among them, 87 of the 1st and 2nd classes are experimental groups, and 83 of the $3 \mathrm{rd}$ and 4 th classes are the control group. . The experimental group adopted a new assessment system. The control group used the usual grade + cartographic major assignment + end-of-session closed-book exam. The usual grades included attendance (40\%), classroom performance $(30 \%)$ and questions $(30 \%)$. One ruler drawing and CAD two-dimensional 
graphic electronic version of the job. The experimental group data are shown in Table 1, and the control group data are shown in Table 2. From the results of the final exam, the experimental group was significantly better than the control group.

Table 1. The experimental group data

\begin{tabular}{|c|c|c|c|c|c|}
\hline \multirow{2}{*}{ Score distribution } & Average score & Highest score & Lowest score & Difficult & distinguish \\
\cline { 2 - 6 } & 65.38 & 89 & 35 & 0.35 & 0.3 \\
\hline
\end{tabular}

Table 2. The control group data

\begin{tabular}{|c|c|c|c|c|c|}
\hline \multirow{2}{*}{ Score distribution } & Average score & Highest score & Lowest score & Difficult & distinguish \\
\cline { 2 - 6 } & 63.71 & 81 & 24 & 0.36 & 0.26 \\
\hline
\end{tabular}

In addition, the instructor also tracked the number of students in the 17th grade civil engineering major who participated in the entrepreneurial innovation project and the undergraduate students participating in the research project after the class ended. The experimental group consisted of 29 people and the control group consisted of 22 people. In 2018 and 2019, they participated in the college. The number of contestants in the contest was 18 in the experimental group and 14 in the control group. The number of participants in the 18-year and 19-year high school cup national university map competition was 3 in the experimental group and 1 in the control group. The number of winners, 1 in the experimental group, and the control group. 0. As can be seen from the above data, the new curriculum assessment system has stimulated students' interest in drawing and research to some extent.

In order to gain a deeper understanding of the real evaluation of the new assessment system, after the completion of the class, the teaching and research section conducted a symposium. Three teachers from the teaching and research section and eight students from the experimental group participated in the discussion. The student representatives reported that the course did not adapt to this method, the amount of work was very large, the drawing process was very cumbersome, and the grades of the course were scattered throughout the course of each assignment, which made some students who were preparing for the pre-test assaults at a loss. However, following the teacher's rhythm, one by one, the progress is very fast. At the end of the period, I look at my own set of drawings and have a sense of accomplishment, and some will also send a circle of friends. In the following study, this part of the course design is handy, and you are more and more confident in professional learning. The regular assessment of the ruler operation promotes the students' efficiency, and the task-driven assessment makes the students take the task to familiarize themselves with the operation commands and communicate with each other. The level of drawing is improved quickly; the comprehensive and open end of the period The test questions will allow students to review the final impact stage and not only focus on the test content, but learn to use knowledge to solve the problem. At the same time, the students also put forward some suggestions. For example, the review part of the drawing is intended to be more detailed by the reviewer. Some computer software versions of the computer room are not updated in time. In response to these problems, the instructors recorded and made corrections.

\section{Summary}

The reform of the assessment mode is an important link in the teaching reform. The establishment of the assessment system breaks the traditional single assessment method, which enables students to shift from passive acceptance to active exploration, from imitation to creation, and also helps teachers from focusing on knowledge transfer to paying attention to students' ability. The transformation of training and quality training truly achieves teaching and learning. In the application of the assessment system, new problems will arise, and new situations will be encountered. This requires our educators to continue to carry out research, continuously improve and improve, and continuously improve the teaching effect of the "Engineering Drawing" course for students. Professional learning lays a solid foundation. 


\section{Acknowledgements}

1.2019 Annual School Education and Teaching Reform Project of Northwest minzu University (Project No.: 2019XJJG-50).

2.2017 Central University Basic Research Business Expenses Project (Project No.: 31920170071 ).

\section{References}

[1]. The Office of the Central Committee of the Communist Party of China, the General Office of the State Council. Opinions on deepening the reform of education system and mechanism [N]. People's Daily, 2017-09-25 (1).

[2]. Xi Jinping. Speech at the Peking University Teacher-Student Symposium [N]. People's Daily, 2018-05-03 (2) .

[3]. Chen Jining. Comprehensively deepen education and teaching reform and vigorously improve the quality of talent training [J]. Tsinghua University Education Research, 2014, 35 (6): 1-5.

[4]. Sun Na. Analysis of the status quo of China's higher engineering education professional certification development and its prospects [J]. Innovation and Entrepreneurship Education, 2016, 17(1).

[5]. Zhang Jianshu, Guo Ruili. Evaluation Reform of Course Achieving Degree under the Background of Engineering Education Certification [J]. Higher Education Forum, 2016, (6): 7274. 